\title{
Effect of Gangue Minerals on Hydrophobic Recovery of Gold
}

\author{
Anderson E. L. Mlaki, Jamidu H. Y. Katima, Henry T. Kimweri \\ Department of Chemical and Mining Engineering, College of Engineering and Technology, \\ University of Dar es Salaam, Dar es Salaam, Tanzania \\ Email: amlaki@udsm.ac.tz
}

Received February 23, 2011; revised February 18, 2013; accepted February 26, 2013

\begin{abstract}
In this paper, the effect of gangue minerals on the hydrophobic recovery of gold is being investigated using ores obtained from the active small scale gold mining sites in Tanzania. Gold ores of different gangue contents were tested. The effects of silica gangue and high sulphide gangue on gold attachment were examined including the effect of surface activators (potassium amyl xanthate) and the possibility of depressing the effects of gangue using reagents. The results were evaluated in terms of gold recovery, volumes and grade of concentrates formed. There was no change in gold recoveries when the amount of oxide gangue (quartz) in the ore was increased, indicating absence of competition between gold and quartz gangue. High sulphide contents in the ore above $6 \%$ reduced gold recoveries considerably. It was noted that potassium amyl xanthate surfactants increased the attachment of both gold and the sulphide gangue. Using lime at pH 10 it was possible to depress the sulphide gangue which is mainly pyrite and hence increased gold recoveries considerably.
\end{abstract}

Keywords: Aggl/Ore Ratio; Gangue Minerals; Hydrophobicity; Surfactants; Gangue Depressants; Oleophilicity

\section{Introduction}

The presence of gangue minerals in gold ores is among the main reasons for the selection of appropriate gold recovery method. The common gangue minerals which are normally associated with gold ores include quartz, fluorite, calcite, pyrites, chalcopyrites, galena and many others in small amounts e.g. arsenopyrites, fluorites, carbonates and chlorites [1,2].

The hydrophobic recovery of gold is dependent on greater oleophilicity and hydrophobicity of gold compared to many other minerals. However it is known that some of the gangue minerals that are associated with gold have oleophilic and hydrophobic properties and the presence of such mineral gangue in the ore may be a source of competition during the attachment to agglomerates. Such minerals include mainly the metallic sulphides gangue $[3,4]$. The presence of low amounts of sulphides in the ore up to $5 \%$ chalcopyrite is reported to have little effect on gold recoveries $[5,6]$.

However, some of the analysed gold ore samples collected from the active small scale gold mining sites in Tanzania indicated the presence of high sulphides upto $12.9 \%$ as shown in Table 1. The presence of high sulphides in Tanzanian gold ores are also reported by [7].

This work is focused on the effects of high sulphides and other gangue on gold recoveries using the hydrophobic recovery of gold. Potassium amyl xanthate was the reagent used as surface activator in the tests. This work was done as a contribution to the ongoing research on the application of the hydrophobic recovery of gold as an alternative to the hazardous use of mercury in small scale gold mining in Tanzania [8].

Table 1. Gold ore mineralogy.

\begin{tabular}{cccc}
\hline \multirow{2}{*}{ Mineral type } & \multicolumn{3}{c}{ Mineral composition \% } \\
\cline { 2 - 4 } & $\begin{array}{c}\text { Chunya } \\
(\text { Ore 1) }\end{array}$ & $\begin{array}{c}\text { Geita } \\
\text { (Ore 2) }\end{array}$ & $\begin{array}{c}\text { Buzwagi } \\
\text { (Ore 3) }\end{array}$ \\
\hline Chalcopyrite CuFeS 2 & 0.21 & 1.16 & 1.09 \\
Pyrite FeS 2 & 7.06 & 9.44 & 11.53 \\
Arsenopyrite AsFeS & 0 & 0.01 & 0 \\
Galena PbS & 0 & 0.25 & 0.3 \\
Quartz SiO & 89 & 79.5 & 75.64 \\
Liberated gold & 1 & 1 & 1 \\
Other minerals & 2.73 & 8.64 & 9.8 \\
Total Mineral & 100 & 100 & 99.36 \\
\hline
\end{tabular}




\section{Experimental}

\subsection{Materials}

\section{a) Agglomerates}

Agglomerate samples were prior formed using castor oil as liquid hydrophobic phase and coal of particle size -110 microns mixed at oil/coal ratio 0.3 . The size of agglomerates used in the tests was $100 \%$ below $2 \mathrm{~mm}$.

b) Gold bearing materials

Three different gold ore samples from SSM areas in Chunya (Ore 1), Geita Gold Mine (Ore 2) and Chocolate reef-Buzwagi (Ore 3) were used.

Main gangue minerals in the three gold ore types were determined as quartzite $\left(\mathrm{SiO}_{2}\right)$, pyrite $\left(\mathrm{FeS}_{2}\right)$, chalcopyrite $\left(\mathrm{CuFeS}_{2}\right)$, Arsenopyrite $\left(\mathrm{AsFeS}_{2}\right)$, and Galena ( $\left.\mathrm{PbS}\right)$. The mineral percentages were determined as per major element analysis which was done with the assistance of the Southern and Eastern Africa Mineral Center laboratory (SEAMIC) as presented in Table 1. Gold contents in each sample were upgraded to $1 \% \mathrm{Au}$, to easy recovery calculations during experimentation. (The ore mineralogy in Table 1 pertain to samples collected for experimentation and do not necessarily represent the particular deposit).

\section{c) Other materials}

Gold powder from small scale mining areas in Chunya. Silica sand (-150 microns) originating from mineral quartz obtained from the defunct Pugu kaolin plant located 25 kilometers from Dar es Salaam. Potassium Amyl Xanthate (KAX) water soluble, $\mathrm{HCl}, \mathrm{HNO}_{3}$, and Lime. Pyrite $\left(\mathrm{FeS}_{2}\right)$ was used to provide incremental sulphide contents in the ores during experimentation. The pyrite was obtained as complement from Geology Department UDSM.

\subsection{Methods}

\subsubsection{Sample Preparation}

The ore samples were ground to $100 \%,-150$ microns. The gold contents in each ore sample were determined by fire assay then upgraded by addition of free gold (minus 150 microns) to $1 \% \mathrm{Au}$. The overall mineral percentage in the ore is shown in Table 1.

\subsubsection{Gold Attachment Tests}

The gold attachment tests were carried out in a $1000 \mathrm{ml}$ beaker equipped with two baffles $180^{\circ}$ apart. The contents were agitated at $700 \mathrm{rpm}$ by a four-bladed stainless steel vertical impeller at $20 \%$ solids and aggl/ore ratio 0.4 . The tests were carried out in the following procedures: (i) Wetting $100 \mathrm{~g}$ of gold bearing material with $500 \mathrm{ml}$ de-ionized water then surfactants such as potassium amyl xanthate was added and/or depressants such as lime was added then agitated for 3 - 5 minutes fol- lowed by (ii) addition of the agglomerate sample and stirring for a given time; (iii) Screening the mixture on a $0.325 \mathrm{~mm}$ sieve in water to separate the gold-loaded agglomerates from the pulp; (v) Drying agglomerates in open air for $6 \mathrm{hrs}$ and weighing them then assessing the recovery of gold by analyzing the amount of gold attached to agglomerates.

\subsubsection{Analysis of Gold Recovered in Agglomerates}

The gold content in the dry agglomerates was analyzed by roasting the dry agglomerates to ash at $500^{\circ} \mathrm{C}$ in a muffle furnace and treating the ash with aquaregia to dissolve gold followed by analysis of the diluted gold solution by atomic absorption spectrometry.

\section{Results and Discussions}

\subsection{Effect of Silica Gangue on Gold Attachment}

Four different sets of samples of increasing silica content were made by addition of silica sand to Ore 3 (lowest silica content). Each of the samples was treated for gold recovery at 60 minute and the recoveries attained did not show any particular relationship with the changes in silica content as shown in Table 2.

According to the results, silica content in the ore did not interfere with gold attachment and hence does not affect gold recovery. This result seemed to agree with the theory that quartz has a strong covalent surface bonding which exhibit high free energy values at the polar surface [9] and therefore during agitation the polar surface of the quartz could have reacted with the water dipoles and making them hydrophilic thus preventing attachment of quartz to agglomerates.

\subsection{Effect of High Sulphide Ores on Gold Attachment}

The effect of high sulphide contents in the ore, was shown by using the three natural ores Ore $1(7.27 \% \mathrm{~S})$, Ore $2(10.6 \% \mathrm{~S})$ and Ore $3(12.9 \% \mathrm{~S})$ with two additional samples prepared to give a wide variation of sulphide contents from 6\% to $15 \% \mathrm{~S}$ as shown in Figure 1. The contact time was varied from 30, 60 and 90 minutes. The gold recoveries determined after each test showed a significant decrease with increase in sulphide content. The highest recovery of $85.1 \%$ was attained by the lower sulphide sample $(6 \% \mathrm{~S})$ at 90 minutes while the high

Table 2. Recoveries attained at different amount of quartz content in ore.

\begin{tabular}{ccccc}
\hline Description & Sample 1 & Sample 2 & Sample 3 & Sample 4 \\
\hline Quartz content \% & 76 & 79 & 81 & 89 \\
Recoveries \% & 75.4 & 77 & 75.8 & 76 \\
\hline
\end{tabular}


sulphide sample $(15 \% \mathrm{~S})$ which had a low recovery of only $72.5 \%$. The same recovery trend (high sulphides content-low gold recovery) was also noted at lower contact time as shown in Figure 1.

The lower recoveries attained due to high sulphides were therefore attributed to natural hydrophobicity and oleophilicity of sulphides which enabled attachment to agglomerate thus creating competition between gold and gangue.

\subsection{Effect of Potassium Amyl Xanthate as Surface Activator on Gold and Gangue Recovery}

Generally there were higher recoveries attained when surfactants were added. As compared to the recoveries attained in the previous Section 3.2, at 6\% sulphide, gold recoveries increased from the previous $85.1 \%$ to $94.0 \%$ at 90 minutes contact as shown in Figure 2.

However, although the recoveries were higher due to the effect of surfactant, they continued to proportionally decrease with increase in sulphide content in the ore. The results indicated that, the action of surfactant increased gold recoveries, but did not affect the attachment competition between gold and sulphide gangue.

\section{4. (i) Effect of Surfactant on Gangue Recovery Measured by Concentrate Weights}

The results of two sample groups which were treated with and without surfactant (Figure 3) and (Figure 4) showed that samples treated with surfactant had higher concentrate weights. The increase in concentrate weight was attributed to increased attachment of both gold and sulphide gangue due to the action of surfactant. The results agreed with previous results that, the action of xanthate surfactant could not decrease attachment competetion between gold and gangue but only promoted attachment of both gold and sulphide gangue as presented in Figures 3 and 4. Higher concentrate weights also showed a decrease in grade as discussed in Section 3.4 (ii).

\section{4. (ii) Effect of Concentrate Weight on Grade}

The concentrate weights were plotted against grades as shown in Figure 5. The grade decreased with increase in concentrate weight indicating high gangue recovery, thus confirming high competition between gold and sulphides. It was therefore necessary to carryout further tests as an attempt to successfully depress the effect of sulphide gangue and reduce competition on gold recoveries as presented in Section 3.5.

\subsection{Depressing the Effects of Gangue on Recovery Using Reagents}

Due to reported effective performance of lime in selective depression of pyrite among other sulphides in copper flotation $[4,9,10]$, slaked lime solution $\mathrm{Ca}(\mathrm{OH})_{2}$ was

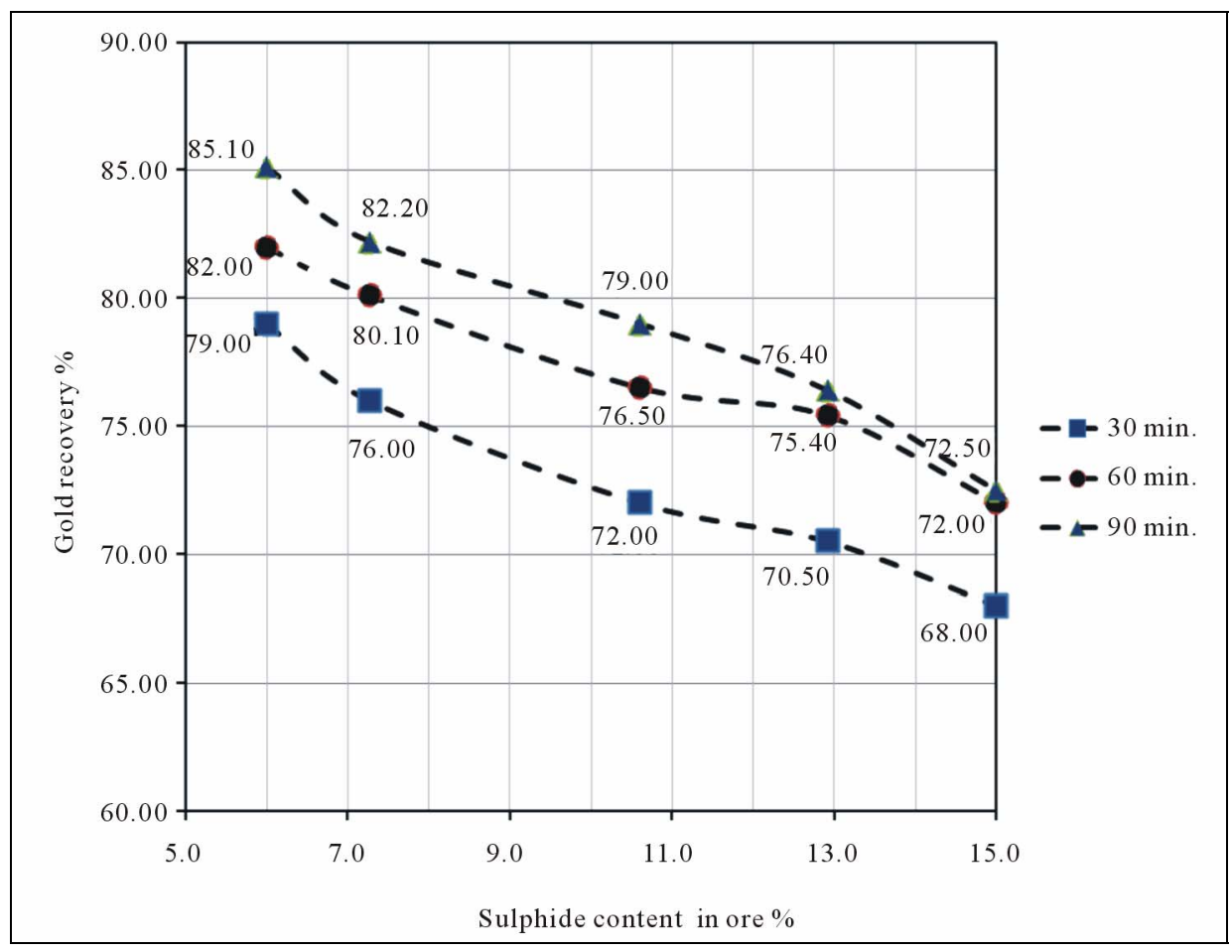

Figure 1. Gold recoveries from high sulphide ores without surfactants. 


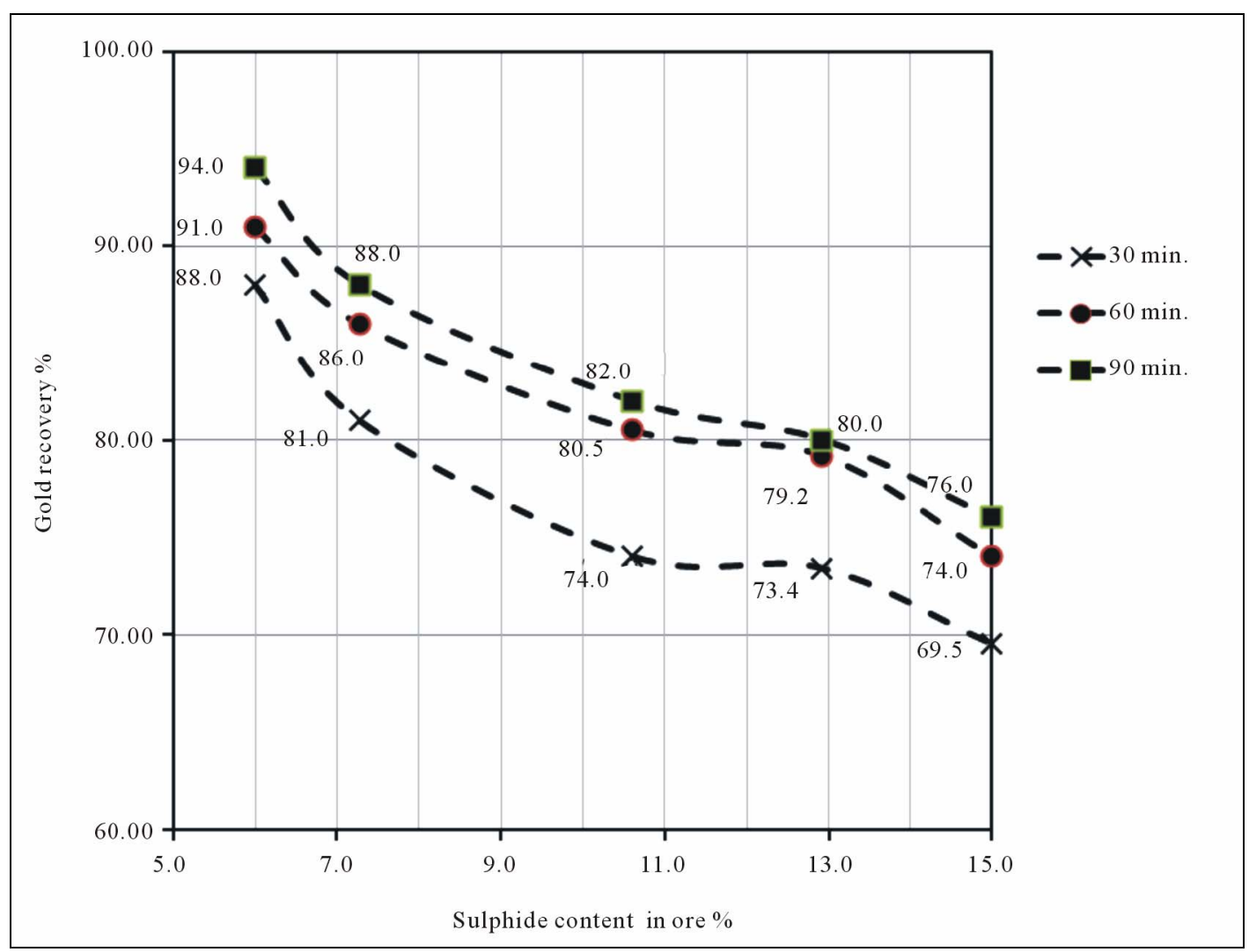

Figure 2. Gold recoveries from high sulphide ores with addition of surfactants.

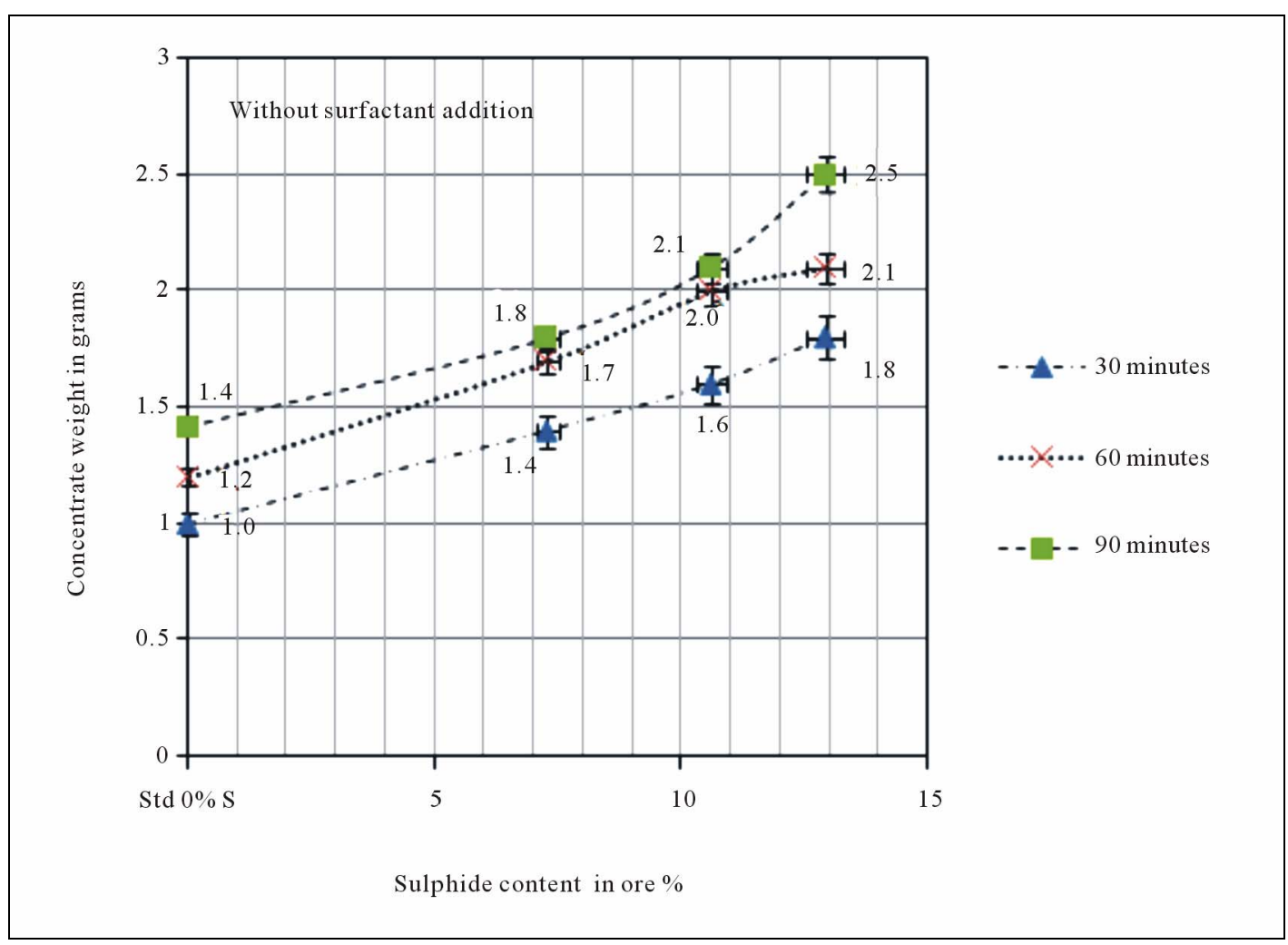

Figure 3. Concentrate weights attained due to gangue recovery (without surfactant). 


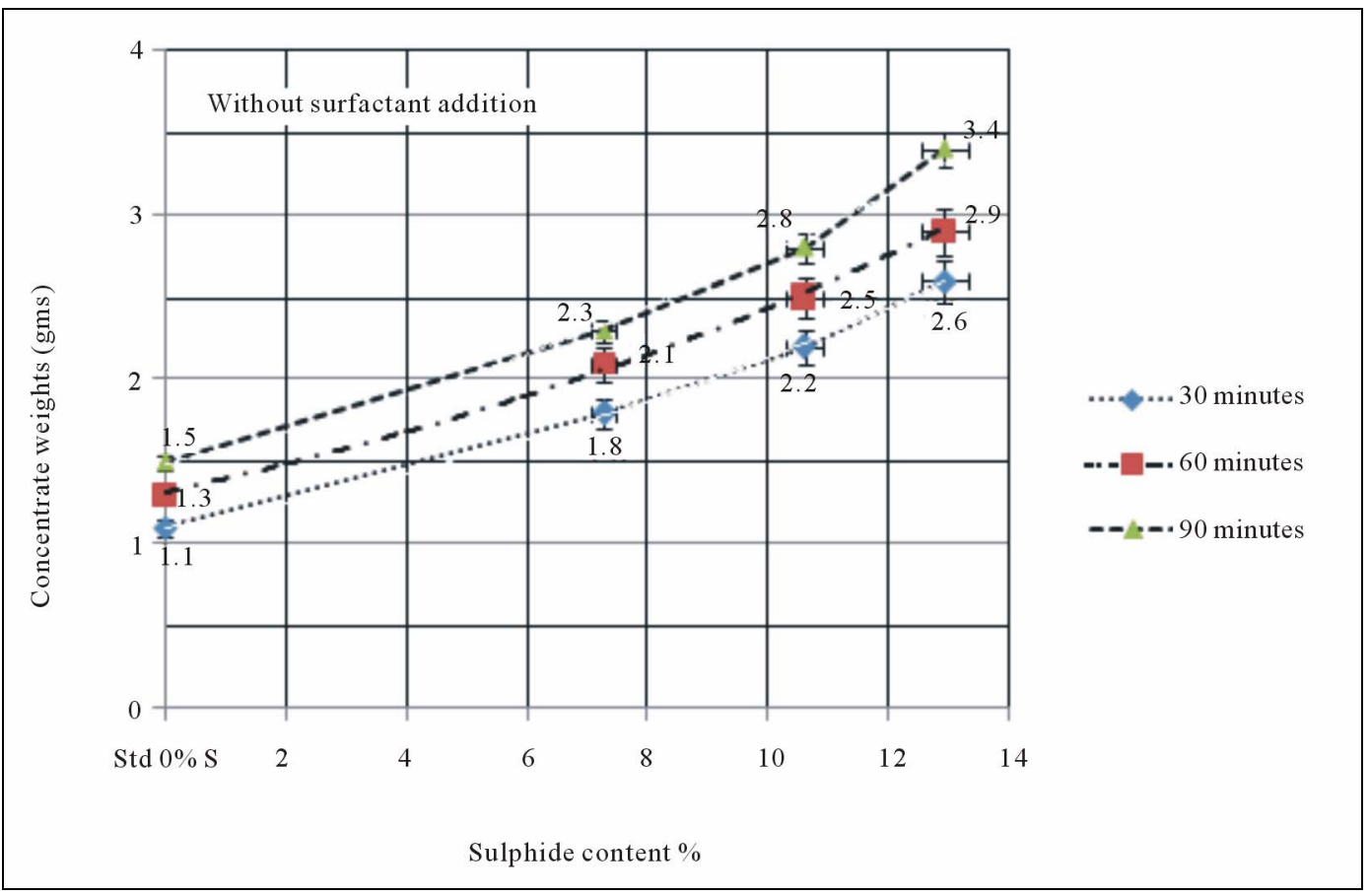

Figure 4. Concentrate weights attained due to gangue recovery (with surfactant).

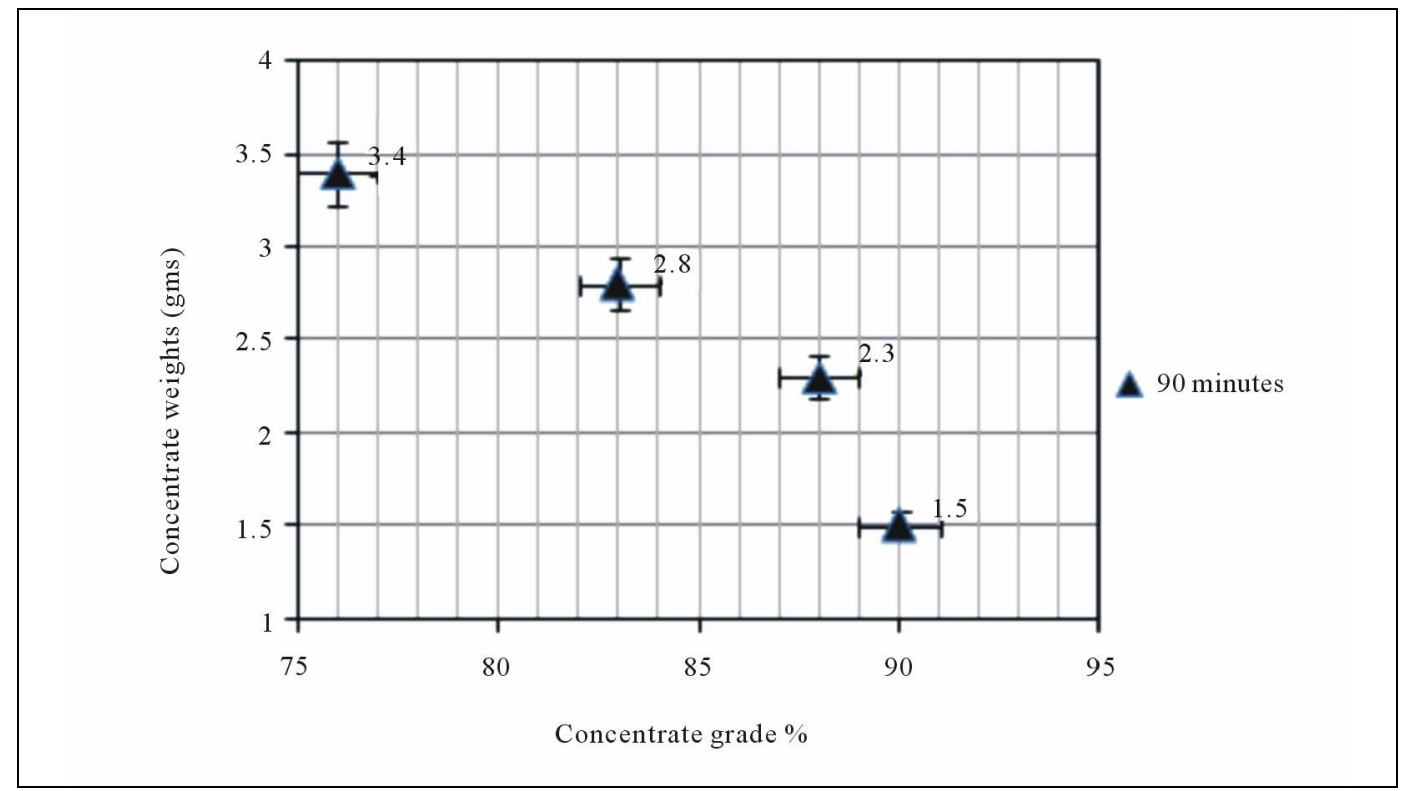

Figure 5. Weights of concentrates formed versus concentrate grade.

prepared and tested as the reagent of choice for gangue depression in the experiments.

The results showed a significant increase in gold recoveries after lime addition to the gold bearing slurries. According to Figure 6, lime showed effectiveness as gangue depressant for all ore samples which contained high pyrite above $6 \%$. This was shown by the changes in recovery between corresponding points on the two curves in Figure 6 when sulphide concentrations were above
$6 \%$. It was noted that pyrite concentrations below $6 \%$ had no effect on gold recoveries and hence the effect of lime could not be noticed in the region. This results agrees with a report by Calvez et al. [6] who reported that sulphide contents higher than $5 \%$ in the ore may have detrimental effects to gold recovery. According to the results it was therefore possible to depress the effect of sulphide gangue (above 6\%) on gold recoveries by using lime at pH 10 as shown in Figure 6. 


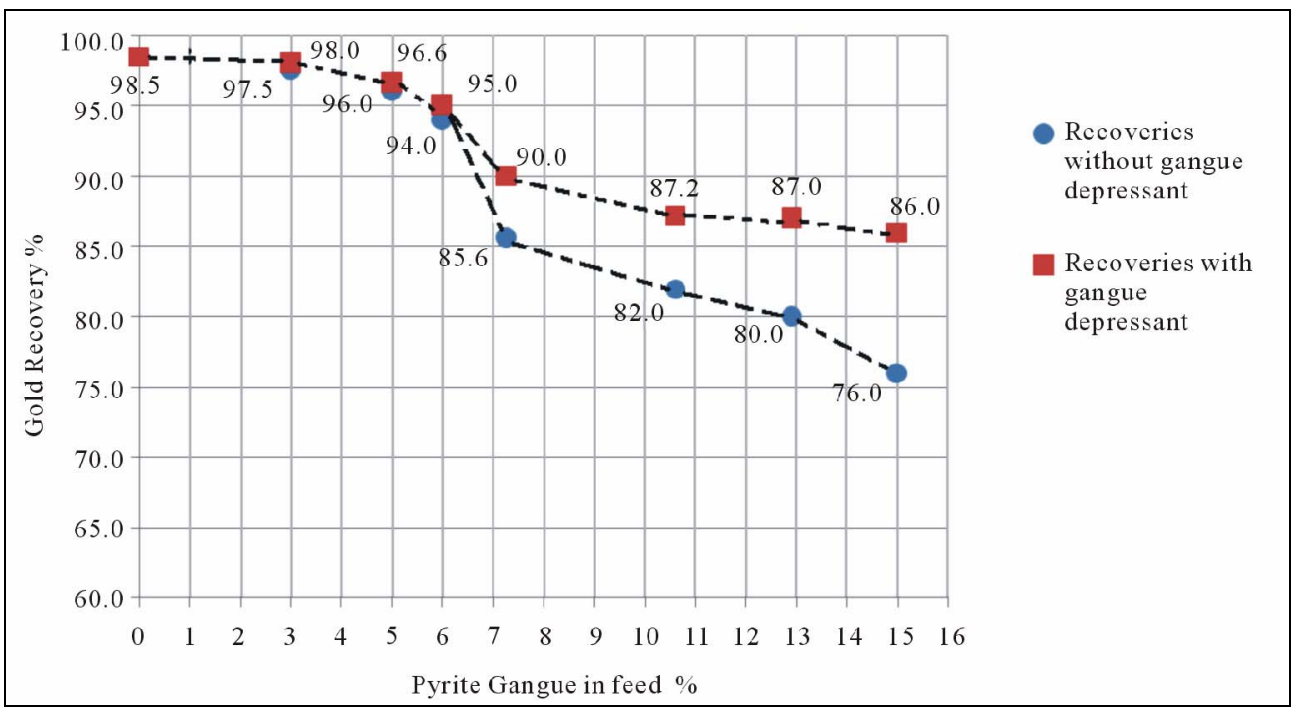

Figure 6. Curves showing gold recoveries before and after pyrite depression using lime at 90 minute contact time.

The depression of sulphide gangue (pyrite) could be explained as due to possible reaction between pyrite surface and lime which changed its natural hydrophobic and oleophilic properties to hydrophilic, reducing its attachment competition.

It is known that the oleophilicity of unoxidised sulphides is decreased due to formation of hydroxides on the surface in alkaline conditions [10,11].

It was therefore necessary to do the attachment tests at $\mathrm{pH} 10$ which was considered alkaline enough for hydroxide formation on the pyrite surface.

\section{Conclusions}

1) The results have shown that the presence of certain types of gangue in the ore may have detrimental effect to gold recoveries in the hydrophobic recovery of gold, e.g. high sulphides contents above $6 \%$.

2) The use of surfactants such as potassium amyl xanthate increased the attachment of both gold and sulphide gangue thus increasing attachment competition.

3) Using lime at pH 10 it was possible to depress the sulphide gangue thus reducing competition on gold attachment to agglomerates and raising gold recoveries considerably.

4) There was no change in gold recoveries when the amount of quartz gangue in the ore was increased, suggesting the existence of quartz particle hydrophilicity due to reaction between the polar surface and the water dipoles.

\section{REFERENCES}

[1] M. John and H. Lain, "The Chemistry of Gold Extraction," Ellis Horwood Ltd., Chichester, 1969.

[2] M. Hausen, "Characterizing the Textural Features of Gold
Ores for Optimizing Gold Extraction," Journal of Mining, Vol. 52, No. 4, 2000, pp. 14-16.

[3] D. Kocabag, G. H. Kelsall and H. L. Shergold, "Natural Oleophilicity-Hydrophobicity of Sulphide Minerals," Imperial College of Science and Technology, Mineral Resources Engineering Department Publications, London, 2003.

[4] B. A. Wills and N. M. Tim, "Mineral Processing Technology; An Introduction to the Practical Aspects of Ore Treatment and Mineral Recovery," 7th Edition, Elsevier Science \& Technology Books, 2006, p. 269.

[5] A. Akcil, X. Q. Wu and E. Aksay, "'Coal-Gold Agglomeration; An Alternative Separation Process in Gold Recovery," Separation \& Purification Reviews, Vol. 38, No. 2, 2009, pp. 173-201. doi:10.1080/15422110902855043

[6] J. P. Calvez, M. J. Kim, P. L. Wong and T. Tran, "Use of Coal-Oil Agglomerates For Particulate Gold Recovery," Minerals Engineering, Vol. 11, No. 9, 1998, pp. 803-812. doi:10.1016/S0892-6875(98)00067-3

[7] R. Brett, "Re-Logging of Diamond Drill Core, Chocolate Reef (Buzwagi), Nzega Greenbelt, North West Tanzania," Exploration Reports, Dodoma, 2001.

[8] A. E. Mlaki, J. H. Katima and H. T. Kimweri, "Gold Recovery from Gold Bearing Materials Using Bio-Diesel, Vegetable Oils and Coal," Engineering, Vol. 3, No. 5, 2011, pp. 555-560. doi:10.4236/eng.2011.35065

[9] D. C. Ronald, "Flotation Theory Reagents and Ore Testing," Pergamon Press, Oxford, 1992.

[10] T. Güler, S. Çetinkaya, Ü. Akdemir, T. Doğan and D. Kocabağ, "Effect of Fe-Ions on Pyrite-Xanthate Interaction in Chemically Manipulated Electrochemical Conditions," International Journal of Natural and Engineering Sciences, Vol. 3, No. 3, 2009, pp. 1-7.

[11] C. Fan, R. Markuszewski and T. Wheelock, "Effect of Multivalent Cations on Oil Agglomeration of Coal and Pyrite," International Journal of Coal Preparation and Utilization, Vol. 11, No. 3, 1992, pp. 167-175. doi:10.1080/07349349208905214 